\title{
Next time you are asked to review a manuscript...
}

John Geissman, University of New Mexico; Chair, GSA

Publications Committee; jgeiss@unm.edu

Hugh Jenkyns, University of Oxford; Editor, Geology; geology@herald.ox.ac.uk

Yildirim Dilek, Miami University; Editor, GSA Bulletin; dileky@muohio.edu

G. Randy Keller, University of Oklahoma; Editor, Geosphere; grkeller@gcn.ou.edu

The timely, effective publication of science requires that the peer-review process functions in an expeditious, thorough, accurate, and fair manner. A critical element of this process is the willingness of individual scientists to conduct informed, objective, and helpful manuscript reviews in a timely fashion. During two meetings at the recent GSA Annual Meeting in Philadelphia, science editors for numerous journals had the opportunity to voice concerns about their all-important volunteer jobs. A unifying theme in these discussions was the inability to find appropriate and, of course, willing reviewers for a significant percentage of the manuscripts submitted. All too often, if potential reviewers actually do provide a reason for declining a manuscript, the common one given is "too busy." Well, most of us are too busy! Yet most (if not all) of us would like to have our own manuscripts reviewed in a timely (and fair and objective) fashion. The difficulty in finding willing reviewers is nothing new, but we are wondering if the level of difficulty, for a myriad of reasons, is increasing. Then add those delinquent reviewers who accept the task but never turn in a review, despite repeated reminders from the editorial office, hence delaying the whole process by weeks, if not months, and causing aggravation for all involved.

We view this problem, which is one that has been gathering increasing attention (e.g., the 29 November 2006, Washington Post article, "Journal editors are urged to demand more evidence," by Rick Weiss, and the 16 December 2006, Science News article, "Peer review under the microscope," by Christen Brownlee), as potentially compromising the whole peerreview process. The rewards for an effective and timely review are, unfortunately, not great, as we all know. However, next time you are asked to review a manuscript, we suggest that you consider taking one of the following three actions, in order of importance and usefulness:

1. Accept, and carry out your review in a timely manner.

2. Decline, but provide a reasoned explanation for declining to review the manuscript, and suggest at least two good potential alternative reviewers for the editor to contact.

3. Decline, but contemplate the possibility that the system is not so flawed that it does not have a memory of those who consistently decline to review manuscripts!

Timely dissemination of the results of good and exciting science in journal articles is only possible through the collective efforts of keen editors and effective referees. GSA Publications honors "Exceptional Reviewers" (see the December 2006 and January 2007 issues of GSA Today) and will continue to do so in the future. Please be one to be recognized!

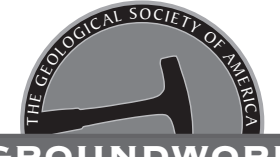

GROUNDWORK

Furthering the Influence of Earth Science

GSA Today seeks articles that lay the groundwork for furthering the influence of earth science on education, policy, planning, and funding. Articles can include in-depth geoscience commentary, short observations and analysis of hot topics, and discussion of policy news and issues.
\end{abstract}

\section{CHARACTERISTICS OF A “GROUNDWORK" ARTICLE:}

(1) The printed article should be a complete, stand-alone article. (Ongoing or serial commentary or meetings summaries are not appropriate for this series.)

(2) Supplemental information may be included as a GSA Data Repository item.

(3) Length: No longer than 1400 words with two small figures or 1600 words with one figure. The philosophy behind this is twofold: (1) keeping an article short can increase the clarity and quality of the writing; and (2) a short article encourages readers to engage and seek more information.

(4) Color figures may be included at no cost to authors.

5 GSA Today science editors will be responsible for review and acceptance of the articles.

6 Frequency: Accepted articles will be published on a space-available basis.

To submit a "Groundwork" article, send your manuscript and figures via e-mail to GSA Today science editors Gerry Ross, lavaboy@hawaiiantel.net, and Stephen Johnston, stj@uvic.ca. 